\title{
LA COLONIALIDAD DEL PODER Y DEL SABER EN LAS POLÍTICAS PÚBLICAS DE LA UNIÓN EUROPEA: Reflexiones a partir de una investigación sobre "inmigración" e "integración"
}

\author{
Luca SEBASTIANI \\ Universidad de Granada (España) \\ lucaseba78@ugr.es, lucaseba78@aibr.org
}

THE COLONIALITY OF POWER AND KNOWLEDGE IN EUROPEAN UNION POLICIES: considerations based on a research about "immigration" and "integration"

Resumen: En este artículo analizo cómo la colonialidad del poder y la colonialidad del saber se manifiestan en las políticas de control migratorio de la Unión Europea y en el "Marco Europeo para la Integración". Planteo que la colonialidad del poder se manifiesta especialmente en las primeras, de una manera directa e "inmediata", mientras que la colonialidad del saber afecta principalmente a las políticas "blandas" de integración comunitarias, aunque de una manera "mediada" y "enmascarada" por variados mecanismos discursivos y no discursivos. En este último espacio, el lugar de enunciación eurocéntrico resulta más eficazmente encubierto por un conjunto de prácticas participativas y de saberes hegemónicos. Concluyo que, a pesar de las diferencias, ambos marcos políticos son complementarios y mutuamente constitutivos, por lo que declaro "ficticia" la separación entre "inmigración" e "integración" y la considero como una "tecnología de poder" con una fuerte dimension de colonialidad.

Abstract: In this paper I analyse how coloniality of power and knowledge reveals itself within both European Union migration control policies and the "European Integration Framework". I suggest that coloniality of power is particularly present in the first policy field, more directly and "immediately", while coloniality of knowledge mainly affects EU soft policies on integration, although in a more "mediated" way, "masked" by various discursive and non-discursive mechanisms. In this latter political field, the eurocentric locus of enunciation is covered-up more efficaciously by a set of participatory practices and hegemonic knowledge. I conclude affirming that, in spite of the existing differences, both political fields are complementary and reciprocally constitutive, therefore I declare "fictitious" their separation and consider it as a "technology of power" with a strong dimension of coloniality.

Palabras clave: Colonialidad del poder. Colonialidad del saber. Unión Europea. Inmigración. Integración Coloniality of power. Coloniality of knowledge. European Union. Immigration. Integration 


\section{Una re-lectura crítica para un diálogo entre perspectivas}

En el presente artículo propondré una re-lectura crítica de los resultados de mi investigación doctoral a partir de la(s) perspectiva(s) decolonial(es). El susodicho estudio estaba fundamentado en unos presupuestos teóricos algo diferentes -aunque no incompatibles- con respecto del acercamiento aquí propuesto.

Mi tesis doctoral ${ }^{1}$ puede ser definida como un análisis contra-hegemónico de las relaciones de poder/saber emergentes en el "Marco Europeo para la Integración", un espacio de gobernanza multinivel implementado por la Unión Europea (UE) en el que participan actores de diversos tipos -instituciones, organizaciones no gubernamentales, "expertos"- y niveles -europeo, nacional, regional o local- a través de políticas "blandas" (soft policies), basadas en el intercambio voluntario de informaciones y buenas prácticas ${ }^{2}$. Enfocando el objeto de estudio desde la perspectiva de la "antropología de las políticas públicas" (Shore y Wright, 1997) y de los "estudios sobre gubernamentalidad" (Foucault, 1991. Rose, 1999. Dean, 2010) y basándome en el trabajo de campo realizado en Bruselas entre 2011 y $2012^{3}$, terminaba resaltando las siguientes conclusiones: 1) el concepto de "integración", utilizado por la UE para problematizar la gestión de las relaciones entre "ciudadanos europeos" y población migrante "no comunitaria", es una una construcción social; 2) sus contenidos y conceptos, a pesar de ser enunciados de una manera "despolitizada" y "técnica", responden a una operación ideológica encubierta antes que a un saber "científico" y "neutral"; 3 ) las prácticas participativas fomentadas al amparo de este marco, dirigidas tanto a las personas migrantes como a las organizaciones supuestamente representativas de ellas, están supeditadas a exigencias de "eficacia" y "eficiencia" en la implementación de las políticas públicas, se encuentran encauzadas dentro de unos "patrones de agencia" típicamente neoliberales y su alcance tiene unos límites pre-establecidos.

El ejercicio practicado en el presente artículo constituye un intento por enriquecer el marco teórico de mi tesis. Mi propósito es el de "abonar" el terreno de elaboración abierto por la investigación doctoral mediante la puesta en diálogo con otras aportaciones, así como de resaltar potencialidades, encrucijadas y tensiones de esta reflexión incipiente. Así pues, realizaré las siguientes operaciones: primero daré por buena la diferenciación, hoy día asentada en muchos entornos académicos, políticos y sociales, entre políticas de control migratorio (y fronterizo) y políticas de integración. A estas alturas, me dedicaré a desentrañar de qué manera las susodichas políticas son afectadas por la "colonialidad del poder" (Qui-

\footnotetext{
1 Titulada "Análisis etnográfico de un dispositivo político transescalar: el marco de la Unión Europea para la integración de nacionales de terceros países" (2014), se trata de una tesis por compendio de publicaciones. Ha sido dirigida por Aurora Álvarez Veinguer y Francisco Javier García Castaño. Su realización ha sido financiada por el Programa 6A del Plan Propio de Investigación de la Universidad de Granada. Este artículo constituye el desarrollo de algunas reflexiones presentadas en una comunicación para el VIII Congreso sobre Migraciones Internacionales en España (2015). Su escritura ha sido subvencionada por el Programa de Fortalecimiento de las Capacidades I+D+i de los grupos de investigación de la Universidad de Granada.

2 Es importante tener en cuenta un aspecto de la arquitectura institucional comunitaria: conforme con el art. 79.4 del Tratado de Lisboa, la UE sólo puede apoyar las políticas de integración de los estados miembros, excluyendo su armonización. En cambio, las políticas de migración, asilo, visado y controles en frontera han sido comunitarizadas a partir del Tratado de Ámsterdam (1997), convirtiéndose en una competencia compartida entre UE y estados miembros. No por menos "coercitivo" el papel de la UE resulta menos interesante: por el contrario, el Marco Europeo de la Integración se ha ido construyendo gracias a una aportación considerable por parte de instituciones comunitarias (como la Comisión Europea y el Comité Económico y Social Europeo) así como de organizaciones no gubernamentales con sede en Bruselas.

3 Consistente en 37 entrevistas hechas a los protagonistas más relevantes de este marco político, numerosas observaciones de encuentros y la lectura de varias fuentes.
} 
jano, 2000) y “del saber" (Lander, 2000a. Mignolo, 2010)4. Lo cual me llevará a teorizar la existencia de dos lógicas distintas, observando que las políticas de control migratorio están particularmente afectadas por la colonialidad del poder y las de integración se encuentran atravesadas principalmente por la colonialidad del saber ${ }^{5}$. También observaré que la primera lógica se manifiesta de una manera más directa e "inmediata", mientras que la segunda es menos evidente ya que su presencia es "mediada" y "enmascarada" por una variedad de mecanismos tanto discursivos como no discursivos. Finalmente, concluiré que a pesar de las diferencias existentes ambos espacios políticos son complementarios y mutuamente constitutivos, por lo que declararé "ficticia" la división entre "inmigración" e "integración" y argumentaré que tal separación es en sí constitutiva de una "tecnología de poder" influida por una relevante dimensión de colonialidad.

Entre los objetivos de este trabajo se encuentra el de buscar líneas de fuga del "pensamiento abismal" (Santos, 2010) moderno-colonial ${ }^{6}$, recogiendo la invitación de Boatcă, Costa y Gutiérrez Rodríguez (2010: 6) a descolonizar las ciencias sociales hegemónicas a través de tres operaciones: "provincializar" (Chakrabarty, 2008: 30), "deconstruir" y "descentrar" Europa incluso desde su proprio interior. Igualmente, esta contribución va en la dirección señalada por quienes critican cierto sesgo eurocéntrico presente en el pensamiento foucaultiano (Castro-Gómez, 2000. Mignolo, 2010: 32) y abogan por "corregirlo" a través de una contaminación con la epistemología decolonial, algunos incluso hablando de "tropicalizar a Foucault" (Kramsch, 2010: 258). También recoge el estímulo de quienes critican el "europeísmo metodológico" ínsito en la mayoría de los estudios migratorios, que acarrea como consecuencia el hecho de "proponer Europa como paradigma para la epistemología de las migraciones, con el resultado de imponer categorías y narrativas Euro-centradas sobre cualquier escenario de movilidad" (Garelli y Tazzioli, 2013: 247. Traducción propia).

Debido a la extensión reducida de este trabajo, me veré obligado a dar por sentadas algunas afirmaciones y a proporcionar ejemplos cuya justificación y relevancia son fundamentadas empíricamente y con más holgura en publicaciones anteriores que forman parte de mi tesis doctoral -a la que remito-. Aunque no tenga la pretensión de extender mis con-

4 Con la primera expresión Quijano (2000) se refiere a la permanencia a nivel global de un patrón de dominación fundamentado en procesos de clasificación (e inferiorización) del "Otro" mediante un sistema complejo (e interseccional) de jerarquías determinado por la "raza" (entendida, por supuesto, como construcción socio-cultural), el género, la clase, etcétera. Este patrón de poder global sobrevive a la independencia de los territorios colonizados por Occidente y permanece aún hoy en día. Con la segunda expresión, Mignolo (2010: 17) remite a la descalificación de todas las formas de conocimiento ajenas a la cosmología occidental moderna, constituida por el binomio teología/ciencia y arraigada en el saber establecido en las universidades europeas. Sobre el origen de estas últimas y el eurocentrismo de las ciencias sociales véanse también Wallerstein (1996: 98), Castro-Gómez (2000) y Walsh (2012).

5 Por supuesto, toda relación de poder implica un saber y viceversa (véase Foucault, 2009); asimismo, "la colonialidad del poder y la colonialidad del saber se encuentran emplazadas en una misma matriz genética" (CastroGómez, 2000: 93). Sólo estoy afirmando que, dentro de las relaciones de poder/saber existentes en este contexto de estudio, la lógica de la colonialidad afecta más a uno de los dos términos según el caso.

6 Sostiene el sociólogo portugués que el pensamiento occidental moderno es abismal porque "consiste en un sistema de distinciones visibles e invisibles", donde a pesar de que "las invisibles constituyen el fundamento de las visibles [...], el 'otro lado de la línea' desaparece como realidad, se convierte en no existente, y de hecho es producido como no existente" (Santos, 2010: 11 y 12). Los territorios coloniales eran zonas sin ley, espacios excluidos del derecho vigente en Occidente: "lo colonial es el estado de naturaleza donde las instituciones de la sociedad civil no tienen lugar" (2010: 16). Asimismo, los saberes producidos por las poblaciones colonizadas no eran considerados conocimientos reales, sino "creencias, opiniones, magia, idolatría" (2010: 14). Lejos de reducirse al pasado histórico, estas líneas abismales siguen caracterizando las sociedades actuales, dado que "la creación y la negación del otro lado de la línea son constitutivas de los principios y prácticas hegemónicas. Hoy como entonces, la imposibilidad de la co-presencia entre los dos lados de la línea se convierte en suprema" (2010: 19). 
sideraciones más allá del contexto estudiado, con este (inevitablemente incompleto) esbozo de análisis espero aportar mi grano de arena a los objetivos arriba formulados.

\section{Las políticas comunitarias de control migratorio y la colonialidad del poder}

Como el bárbaro se opone al proceso civilizador, la praxis moderna debe ejercer en último caso la violencia si fuera necesario, para destruir los obstáculos de tal modernización

[...] Esta dominación produce víctimas (de muy variadas maneras), violencia que es interpretada como un acto inevitable, y con el sentido cuasi-ritual de sacrificio [...] Para el moderno, el bárbaro tiene una 'culpa' (el oponerse al proceso civilizador) que permite a la Modernidad presentarse no sólo como inocente sino como 'emancipadora' de esa 'culpa de sus propias víctimas'

(Dussel, 2000: 29)

Los Derechos Humanos son así violados con objeto de ser defendidos, la democracia es destruida para salvaguardar la democracia, la vida es eliminada para preservar la vida

(Santos, 2010: 24)

Hay que hundir los barcos. No queda otra solución. Mejor un acto de guerra que perder la guerra (Daniela Santanché, dirigente del partido "Forza Italia" y parlamentaria italiana. Redazione Huffington Post, 2015.

Traducción propia)

En la noche entre el 18 y el 19 de abril de 2015, un barco ocupado por casi mil inmigrantes, procedentes de distintos países de África y Asia y dirigido a las costas italianas, se vuelca en aguas libias durante un intento de rescate por parte de un carguero portugués ${ }^{7}$. Los medios afirman que es la mayor tragedia vivida por el Mediterráneo (Ordaz, 2015. Marceca, Viviano y Ziniti, 2015). Se genera un debate en Italia, entre las críticas de organizaciones humanitarias a la operación "Tritón" de la UE, acusada de primar una lógica de control fronterizo en lugar de salvar vidas (Repubblica.it, 2015a) y las declaraciones de políticos xenófobos que invocan el bloqueo naval o el hundimiento de los barcos (Repubblica.it, 2015b). Aunque este suceso sea una de las manifestaciones más horribles de la violencia ejercida en/por las fronteras (geográficas, sociales y políticas) ${ }^{8}$ europeas, no es el único. Sólo para limitarnos a la "Frontera Sur", cabe recordar la reciente legalización de las (ya practicadas) devoluciones "en caliente" en el ordenamiento jurídico español, contrarias al derecho de asilo y refugio e incluidas en la reforma de la Ley Orgánica de Seguridad Ciudadana, también conocida como "Ley Mordaza" (García, 2015). Más allá de la medida en

7 Soy bien consciente de los sensacionalismos y los estereotipos "victimistas" proyectados sobre la migración "no comunitaria", así como de las retóricas de las "pateras" y los "asaltos" a las vallas (véase Santamaría, 2002). Nada más lejos de mis intenciones está contribuir a reforzar las narrativas de hiper-visibilización que caracterizan el "espectáculo de la frontera" (De Genova, 2015) y la "industria de la ilegalidad" (Andersson, 2014). Con lo cual, la elección en este apartado de ejemplos "trágicos" es de achacarse a la necesidad de argumentar por qué razones afirmo que las políticas migratorias están atravesadas por una marcada colonialidad del poder. Asimismo, el hecho de que me centre en la deconstrucción de representaciones hegemónicas y "desempoderantes" no me lleva bajo ningún concepto a minusvalorar el papel de la subjetividad migrante como "actor fundamental de reorganización, cuestionamiento y redefinición de los límites de la ciudadanía” (Mezzadra y Nielson, 2014: 19). 8 En este texto la noción de frontera es entendida desde una acepción amplia, no solamente geográfica (véanse Balibar, 2003. Dal Lago, 2005. Casas, Cobarrubias y Pickles, 2011. Mezzadra y Nielson, 2014). 
sí, el hecho de que sea incorporada a la susodicha ley produce una representación de las migraciones estrechamente vinculada a un escenario de alteración del orden público -el migrante es social y legalmente construido como una "amenaza a la seguridad" (Andersson, 2014: 68)-. Otro dramático ejemplo, de hace un año, es la muerte de 15 migrantes subsaharianos en la playa de Tarajal (Ceuta), cuando aún en el agua y en el intento de cruzar la línea fronteriza recibieron disparos de balas de goma a manos de la Guardia Civil (Cúe y Jiménez Gálvez, 2014). También podrían mencionarse los controles de identidad en las vías públicas españolas llevados a cabo por la Policía Nacional mediante el uso de perfiles étnicos, una práctica prohibida por la Carta de los Derechos Fundamentales de la Unión Europea (art. 21) y aun así extendida como algo común y cotidiano (Amnistía Internacional, 2011. Brigadas Vecinales de Observación de Derechos Humanos, 2012). Yendo atrás en el tiempo, cabe nombrar los campos de detención para inmigrantes "irregulares" en espera de expulsión, establecidos a partir de los años noventa en prácticamente todos los países europeos (véase Migreurop, 2014).

Todos los citados acontecimientos guardan algún tipo de relación, más o menos directa, con las políticas de control migratorio de la UE. Sin ir más lejos, el estatus de los centros de detención ha sido regulado, y por tanto reconocido, por la "Directiva de Retorno" 2008/115/ $\mathrm{CE}$, votada sin enmiendas por el Parlamento Europeo y rebautizada por diferentes colectivos como "Directiva de la Vergüenza". Otros sucesos, aun pudiendo imputarse al celo represor de determinados gobiernos, no dejan de ser el producto de una lógica seguritaria que afecta al conjunto de las políticas migratorias europeas. En lo que respecta al citado naufragio en aguas libias, resultan esclarecedoras las observaciones del parlamentario europeo Miguel Urbán (de la formación "Podemos"), que relata en el blog de Publico.es su propia experiencia en esta institución:

"El pasado lunes en la Comisión de Economía y Presupuestos del Parlamento Europeo guardamos un minuto de silencio por las recientes muertes de las personas migrantes en el Mediterráneo. Al terminar, las y los representantes de nuestro grupo parlamentario (Izquierda Unitaria Europea GUE/NGL) solicitamos un receso de 10 minutos en la comisión para poder participar en la concentración que diferentes asociaciones pro Derechos Humanos y de migrantes habían convocado a las puertas de la Eurocámara. Solicitud que fue rechazada porque, según nos respondieron desde la mesa, ya habíamos manifestado nuestras condolencias con esos 60 segundos de silencio. Una actitud esta de las instituciones europeas y sus principales partidos que contrasta obscenamente con la sobreactuación que suele acompañar a otros desastres y tragedias. Hace apenas dos meses todas las actividades europarlamentarias se paralizaron y su extensa plantilla y representantes fuimos convocados a manifestar pública e institucionalmente nuestro rechazo y condolencias ante la brutal matanza perpetrada contra el semanario satírico Charlie Hebdo. La gravedad del acontecimiento así lo requería. Sin embargo, no justifica un receso de 10 minutos la muerte de cerca de 1.000 personas frente a las costas europeas, macabro chorro de agua fría a un mar convertido en fosa común por el goteo incesante de muertes. Cuando hay condolencias de primera y segunda clase, lo que se nos está diciendo es que también hay muertos de primera y de segunda" (Urbán, 2015).

La analogía entre el contenido de las citas que abren este apartado y los sucesos reseñados posteriormente es manifiesta. Las violencias, los dobles raseros y las descalificaciones de derechos y vidas humanas relatados en las anteriores líneas, al conectarse con procesos de clasificación (e inferiorización) de los migrantes no comunitarios basados en un 
fuerte componente de racialización, muestran la clara presencia de un patrón colonial de poder. Esta colonialidad del poder es también evidente en diferentes documentos oficiales de la UE, como por ejemplo la reciente Comunicación de la Comisión Europea sobre "Una Agenda Europea de Migración" de mayo de 2015. Este texto, profundamente vertebrado por una lógica de "emergencia humanitaria" originada (según se afirma) por los últimos acontecimientos en el Mar Mediterráneo, establece una fuerte vinculación entre la migración "irregular" y un imaginario marcado por la idea de "vulnerabilidad" del migrante, así como por la naturaleza delictiva de las "mafias" que se aprovecharían de él/ella, definidas "redes criminales que ponen su beneficio por encima de la vida humana" (COM(2015) 240 final: 8). En esta línea, hace un continuo llamamiento a "atajar la miseria humana creada por quienes explotan a los migrantes" $(\mathrm{COM}(2015) 240$ final: 2), a perseguir "las redes delictivas que explotan a los migrantes vulnerables" (COM(2015) 240 final: 4) y a conseguir la "identificación, captura y destrucción sistemática de las embarcaciones utilizadas por los traficantes" (COM(2015) 240 final: 4).

Como puede verse, las representaciones de la "guerra" y la "violencia" remiten no sólo a la opinión pública o al debate político cotidiano, sino también a la producción de discursos institucionales. Por otra parte, el verdadero mantra sobre los "traficantes" y "tratantes" no sólo simplifica, iguala y criminaliza las multiples prácticas migratorias existentes al margen de la legalidad, sino que también es utilizado para justificar iniciativas de promoción de la "estabilidad" en los terceros países, empezando por Siria y Libia (COM(2015) 240 final: 7). La construcción de este relato es emprendida sin mencionar responsabilidad alguna que puedan tener la UE o sus estados miembros en las actuales "crisis humanitarias" de África Septentrional y Oriente Prójimo. Éstas aparecen como una exterioridad dada, real pero producida en un afuera absoluto, más allá de una línea abismal que, de no ser por la llegada de inmigrantes a las costas europeas, parecería no mantener ninguna otra conexión con la UE. La "pobreza", las "guerras", las "hambrunas", simplemente parecerían acontecer, sin más, mostrando cómo la colonialidad se insinúa en la misma construcción del relato. Estos tipos de problematizaciones parecen confirmar la intuición de Coronil, quien afirma que tanto los discursos del "occidentalismo" -típicos del período colonial- como los posteriores, y más políticamente correctos, discursos del "globocentrismo" -típicos de la era de la globalización y característicos de las instituciones comunitarias- contribuyen a oscurecer "la mutua constitución de 'Europa' y sus colonias” (2000: 54).

La Agenda Europea de Migración también reseña las más recientes operaciones de patrullaje en el mar, desde la italiana "Mare Nostrum" hasta las operaciones conjuntas "Tritón" y "Poseidón", realizadas bajo el mandato de la "Agencia Europea para la Gestión de la Cooperación Operativa en las Fronteras Exteriores" (FRONTEX). La comunicación continúa resaltando la importancia del "Sistema Europeo de Vigilancia de Fronteras" (EUROSUR, lanzado en 2013), inspirado a su vez en el "Sistema Integrado de Vigilancia Exterior" (SIVE) español. Todas las citadas operaciones hacen un amplio uso de aparatos tecnológicos de varios tipos. Por ejemplo, el SIVE permite que, desde una sala de control a cientos de kilómetros de distancia del lugar donde acontecen los hechos, sea posible identificar una embarcación y monitorear sus movimientos como en un vídeo-juego, transformando las personas migrantes en una mera "anormalidad en la pantalla" (Andersson, 2014: 85-86). Igualmente, en la sede central de FRONTEX en Varsovia, el/la migrante se convierte, a través de su representación geométrica en monitores y pantallas de control, en una abstracción despersonalizada que es definida como una "fuerza" o una "presión" (Andersson, 2014: 77-78). La lógica tecnocrática subyacente en el conjunto de estas iniciativas es tal que, según el testimonio de algunos representantes de una ONG europea por mí entrevistados, ha sido prácticamente imposible llevar el debate sobre EUROSUR a la opinión pública, dado que sus promotores lo han presentado como una cuestión puramente tecnocrática y fuera del alcance de cualquier debate (entrevista del 4/6/2012). A pesar de este reduccionismo 
tecnológico y tecnocrático, el documento no deja de estar atravesado por una fuerte lógica orientalista, por ejemplo a la hora de alabar la iniciativa "Fronteras Inteligentes" (Smart Borders), un sistema de control establecido con el objetivo de facilitar el paso fronterizo a los viajeros definidos "de buena fe" e impedírselo a los "irregulares" (COM(2015) 240 final: 13). Aquí el imaginario de sospecha activado por la expresión "de buena fe" manifiesta cierta analogía con el tópico, tradicional del orientalismo, del árabe de poco fiar, caracterizado por una "deshonestidad sanguinaria" y capaz de "tramar intrigas tortuosas", tal como ha sido descrito por Said (1990: 38), o con el recelo que rodea a la figura de Tariq Ramadan, "reformador" del Islam europeo y constantemente cuestionado por su supuesta ambigüedad, tal como ha sido discutido por Grosfoguel y Mielants (2006: 11).

El análisis del anterior documento, y la constatación de su coherencia discursiva con respecto de los escenarios anteriormente trazados, refuerza el argumento de que las políticas comunitarias de control migratorio (y sus consecuencias) están caracterizadas por una colonialidad del poder claramente "visible", que se percibe de manera "inmediata". Es cierto que el creciente recurso a la externalización de las fronteras y a las citadas tecnologías de control tiende a alejar, ofuscar y producir como invisible parte de las violencias que tienen lugar en las fronteras o en sus inmediaciones -o cuando menos tiende a despersonalizar las responsabilidades humanas y políticas de dichas violencias-. Sin embargo, no consiguen borrar del todo las formas más "brutales" en las que se presenta la colonialidad del poder. Por otra parte, los discursos "humanitarios" impulsados por las propias instituciones comunitarias -cabe añadir, enunciados casi siempre desde un posicionamiento paternalista y de "apiadada compasión" ante el Otro inmigrante- son utilizados como pretexto para el reforzamiento del control migratorio y como justificación de ulteriores medidas restrictivas/reguladoras ${ }^{9}$ de la libertad de movimiento (Gil, 2003: 14-15). Así pues, a pesar de la creciente reducción "tecnocrática" de las políticas de control migratorio, a pesar del uso de un lenguaje cada vez más despolitizado (Andersson, 2014: 77-78) y a pesar de la retórica humanitaria latente, el entramado discursivo del control migratorio y sus implementaciones materiales no dejan de estar marcados por una dimensión tecnológica/militar y seguritaria, donde siempre es posible el recurso a la violencia -por muy desactivado que pueda estar en un momento dado-. Violencia que, a su vez, se legitima por un proceso de (interiorización de la) inferiorización y racialización del Otro. Tal vez, entonces, la posibilidad de la violencia no constituya una excepción a la regla, sino que es indicativa de un "estado de excepción" permanente (Agamben, 2004), el cual habita un espacio (social, legal y geográfico) colonial "sin ley", colocado ontológicamente al otro lado de la línea abismal. Como veremos, esta lógica es muy diferente de la que opera en el Marco Europeo para la Integración.

\section{El "Marco para la Integración" de la Unión Europea y la colonialidad del saber}

En función de las especificidades indicadas anteriormente (nota al pie n. 2), el Marco Europeo de la Integración resulta un ámbito privilegiado para analizar cómo algunas instituciones comunitarias -especialmente la Comisión Europea y el Comité Económico y Social Europeo- elaboran discursos que llevan implícita una concepción de la identidad y los valores "europeos", ensalzándose a sí mismas por un enfoque "abierto" e "inclusivo" que suele ser contrapuesto a las políticas "restrictivas" de algunos países y a los "egoísmos nacionales". En el presente apartado me dedicaré a resaltar la colonialidad implícita, aunque no tan visible como en el anterior caso, dentro de este espacio de enunciación, ilustrando y re-interpretando algunos de los resultados de mi tesis a través de la(s) literatura(s) decolonial(es).

Ahora bien, el propio concepto de integración remite a un imaginario moderno-colonial

9 Añado "reguladoras" a "restrictivas", al entender las fronteras como dispositivos de "inclusión/exclusión diferencial" y no de restricción de la circulación sin más (Mezzadra y Nielson, 2014). 
y eurocéntrico. Como bien recuerda Gil, es difícil nombrar este término sin pensar en la distinción durkheimiana entre solidaridad mecánica y solidaridad orgánica (2006: 398). Cuando, muchas décadas más tarde, la expresión empieza a difundirse como forma de problematización de la presencia migrante -grosso modo a partir de los años setenta en los contextos nacionales europeos y a finales del siglo XX entre las instituciones de la UE-, se hace imposible no pensar en su conexión con las diferentes formas históricas utilizadas por las potencias coloniales para interaccionar con las poblaciones colonizadas. Así pues, los actuales discursos sobre la integración de inmigrantes, independientemente de su variedad, no conllevan una relación de igualdad sino que son discursos "sobre las formas de identificación, tanto de nativos como de extranjeros, y de manera más definitiva, sobre las relaciones de poder desiguales que estas identificaciones implican [...] El estatus emigrante/inmigrante no es sólo una categoría jurídica, sino también (y sobre todo) una categoría social y racial (Gil, 2010: 190)".

A pesar de lo dicho, en mi investigación doctoral emerge que las instituciones impulsoras del Marco Europeo de la Integración han tratado de definir un concepto "no asimilacionista", "bidireccional" y "proactivo" de la misma, parcialmente divergente de las retóricas asimiladoras nacionales y centrado en conceptos como "participación", "inclusión" o "ciudadanía activa", así como orientado por un contenido "cívico-político" antes que "culturalista-etnocéntrico". Al menos, a primera vista: aquí ilustraré que incluso esta perspectiva está influida por una pronunciada colonialidad (en este caso principalmente del saber), aunque sea de manera "mediada" y mucho menos directa que en el caso de las políticas de control migratorio. Para argumentarlo, seleccionaré unos ejemplos concretos.

\subsection{Los supuestos subyacentes en el discurso sobre los "valores europeos"}

A lo largo de la primera década del nuevo siglo se ha observado la gradual introducción, en las legislaciones de numerosos estados miembros, del así llamado "test cívico" (véase Van Öers, Ersboll y Kostakopoulou, 2010) de integración. Más allá de las diferencias entre cada medida nacional, este instrumento ha sido empleado para supeditar la obtención del permiso de residencia, el estatus de residente de larga duración, la reagrupación familiar o la nacionalidad (según el caso) al conocimiento de la "lengua" y las "costumbres" del país receptor ${ }^{10}$. Es más: numerosos documentos de la UE, aun expresando ciertas críticas sobre un uso del test a veces "equivocado" por parte de los estados miembros -orientado a reducir la presencia de inmigrantes antes que a favorecer su integración-, han retomado y "ratificado" esta medida. En una línea parecida, los once "Principios Básicos Comunes" (PBC) de la Unión Europea sobre la integración demandan a la persona inmigrante el respeto a los "valores básicos de la UE" (PBC n. 2) y el conocimiento del idioma y las costumbres de la "sociedad de acogida" (n. 4) (Consejo de la UE, 2004). He aquí un desliz semántico en el que los valores nacionales se convierten en valores europeos. ¿Pero cuál es el contenido de dichos valores? En mi trabajo de campo he refrendado que los principales actores comunitarios adoptan una acepción "cívico-democrática" de los mismos, primando el "respeto a los derechos humanos" y celebrando las "libertades democráticas" que caracterizarían las sociedades europeas "abiertas".

Sin embargo, desde un enfoque decolonial debería quedar claro que este discurso, a pesar de contraponerse al "oscurantismo" achacado a los enfoques más "asimilacionistas" y "culturalistas" de ciertos estados nación, no deja de estar marcado por una colonialidad del saber. Es más: tanto los supuestos básicos del discurso "cívico-democrático" como los fundamentos del discurso "culturalista" remiten a un claro horizonte eurocéntrico. En efecto, la democracia y los derechos humanos de los que se está hablando son asumidos de manera

10 Aunque no quede espacio para argumentarlo, el uso instrumental de ciertas medidas como formas de control migratorio remite a la más general subordinación de las políticas de integración a las de migración. 
desproblematizada como una creación de la "civilización" europea -y solamente de la europea-, que parece haberse auto-generado "sin contacto histórico alguno con otras culturas" (Castro-Gómez, 2000: 92). La historia de esta "civilización", a su vez, es presentada desde una lectura teleológica y retrospectiva (Coronil, 1996: 53) y está arraigada en una "diacronía unilineal Grecia-Roma-Europa" (Dussel, 2000: 24) que presenta a las culturas griega y romana antiguas como precursoras y núcleo fundacional de las sucesivas evoluciones hacia el mundo cristiano medieval, desembocando en la Europa moderna de la Ilustración y en la democracias occidentales (Dussel, 2000: 26), para terminar con la actual Unión Europea que aparece como producto necesario y suprema encarnación del proceso histórico (Balibar, 2009: 6). En otras palabras: la contraposición entre valores "cívico-democrático" y valores "culturalistas" enfatizada por ciertas actores no deja de ser una oposición interna al pensamiento eurocéntrico. Esta aparente dicotomía manifiesta una clara analogía con otra oposición típica de la colonialidad del saber, aquélla entre "teología" y "ciencia". Mignolo ha puesto de relieve cómo ambas formas de conocimiento, a pesar de luchar la una contra la otra en el "más acá" de la línea abismal, en la metrópolis, se convertían en aliadas al otro lado de la "diferencia colonial" (Mignolo, 2003: 112), en los territorios coloniales, descalificando conjuntamente toda forma de conocimiento ajena a la cosmología occidental moderna (Mignolo 2010: 17). Por lo cual, el discurso sobre los valores europeos, a pesar de las resignificaciones existentes se presenta como un discurso de poder y como una forma de aquel universalismo abstracto y "descarnado" del que hablara Césaire en su famosa carta a Maurice Thorez (Césaire 2006: 84. Grosfoguel, 2010: 93- 94). Este discurso no deja de tener vertientes excluyentes, al no ser capaz de valorar las aportaciones que puedan llegar desde fuera de su propio paradigma autocentrado.

\subsection{La implementación de formas participativas específicas}

La Unión Europea apoya diferentes plataformas de participación de la "sociedad civil" tanto al nivel comunitario como al nivel estatal y local; únicamente me centraré en el primer plano. Por supuesto, el propio concepto vertebrador de esta lógica participativa europea origina de otra dicotomía profundamente arraigada en la modernidad occidental, como es la de "Estado" vs. "Sociedad Civil" (Lander, 2000b: 10). Se trata así de una idea profundamente cargada "con el peso del pensamiento y la historia de Europa" (Chakrabarty, 2008: 30). Pero vayamos a analizar un ejemplo concreto, el del "Foro Europeo sobre la Integración" (lanzado en 2009), un espacio de diálogo entre instituciones europeas y organizaciones no gubernamentales consideradas representativas de los intereses migrantes. En mi investigación doctoral he observado que por parte de los actores comunitarios hay un claro compromiso para que se lleve a cabo una participación "activa" dentro de esta plataforma; activa y sin embargo "encauzada" dentro de un marco "reactivo". Es decir: limitada a responder a la producción legislativa institucional, no autorizada para cuestionar la agenda política de fondo y orientada a la búsqueda del "consenso" -en última instancia, ciega ante la dimensión conflictiva de la democracia (véanse Mouffe, 2007. Balibar, 2009)-.

En cuanto al funcionamiento del Foro, la mayoría de los actores invitados a participar suelen ser organizaciones que trabajan "sobre" la migración, a menudo desde una perspectiva humanitaria influida por una vocación religiosa generalmente cristiana (véase Carrera y Parkin, 2010) -un ejemplo entre todos, "Caritas Europa"-. Raros son los casos de organizaciones de migrantes dirigidas por migrantes. Es cierto que las dificultades subrayadas por los actores comunitarios son reales -por ejemplo, los obstáculos existentes para los propios migrantes a la hora de constituir organizaciones representativas de sus intereses al nivel europeo- y que diferentes iniciativas institucionales han subvencionado la constitución de estructuras de este tipo. Lo cual no quita que las racionalidades, las formas representativas y los modelos organizativos implementados dentro del Foro están marcados por un fuerte 
patrón eurocéntrico. Además, hay que tener en cuenta el marco participativo general de la UE, enunciado claramente en el "Libro Blanco sobre la Gobernanza Europea", el cual exige a las organizaciones de la sociedad civil la aplicación de principios de "buena gobernanza", "apertura", "participación", "responsabilidad", "eficacia" y "coherencia" hacia su propio interior (Armstrong, 2001: 11); es decir, requiere que apliquen los mismos principios que han de ser respetados por las instituciones públicas. Estas exigencias representan un claro intento por moldear las formas organizativas de dichas organizaciones y terminan por favorecer la emergencia de determinados tipos de actores -los más poderosos y en particular aquéllos más entrenados en la práctica, históricamente norteuropea, del lobbying-. En este contexto, dentro del Foro para la Integración queda muy poco espacio para actores no hegemónicos, para organizaciones que no estén formalizadas según criterios asociativos, menos aún para organizaciones que reivindiquen derechos desde un posicionamiento externo al marco legal de la UE, como por ejemplo colectivos de migrantes indocumentados ${ }^{11}$. Como añadido, algunos participantes en el Foro -bien integrados en las lógicas participativas hegemónicas pero procedentes del Sur de Europa- han lamentado la prevalencia de un acercamiento demasiado "norteño" a las políticas de integración y a sus prioridades (entrevista del 12/6/2012) $)^{12}$.

\subsection{Despolitización/tecnificación de los saberes y dicotomía razón/emoción}

Si la creciente "tecnocratización" del control migratorio se da mediante el despliegue material de aparatos de control altamente tecnológicos e informatizados, en el Marco Europeo para la Integración acontece un proceso paralelo de "despolitización" y "tecnificación" del contenido de las políticas públicas, el cual en este caso opera sobre todo en el ámbito de los saberes producidos, que se van configurando como "saber experto".

Durante mi investigación doctoral he podido refrendar que la integración es considerada por la UE un tema muy "candente" y "sensible". Las instituciones comunitarias afirman que la inmigración no comunitaria es percibida por amplios sectores de la población autóctona de una manera "irracional", "sensacionalista" y "emotiva", potencialmente aprovechable por los "populismos". De ahí la necesidad de un enfoque "equilibrado" y "no ideológico", "basado en la evidencia" y "fiel a la realidad", tal como reiteran numerosos documentos oficiales y como han afirmado variados actores por mí entrevistados. Esta lógica está particularmente presente en la idea de intercambio de "buenas prácticas", donde su presunta "bondad" no está relacionada con lugar de enunciación alguno; en otras palabras, no se especifica para qué o para quién son o deben ser buenas. Aquí emerge una noción de saber pacificado y acumulativo, no atravesado por relaciones de poder y básicamente auto-suficiente. En este patrón, el simple intercambio de datos "objetivos", "científicos" y "racionales" entre diferentes actores es suficiente como garantía de una mejora en las políticas publicas. En mi tesis definía esta operación como un encubrimiento ideológico de la racionalidad neoliberal implícita en el Marco Europeo para la Integración. Desde un acercamiento decolonial, es posible enriquecer la anterior reflexión poniendo de relieve la

11 Es cierto que durante mi trabajo de campo la "Plataforma Internacional para la Cooperación sobre Migrantes Indocumentados" (PICUM) estaba representada en el Foro para la Integración. Sin embargo esta plataforma, integrada principalmente por asociaciones de tipo caritativo, tuvo que pelear mucho para ser admitida a los trabajos del Foro, dado que su foco de interés (la migración indocumentada) quedaba fuera del alcance legal comunitario, al ser los migrantes "irregulares" objeto de medidas de retorno pero no de integración. Y en todo caso era una plataforma "sobre" la migración indocumentada, liderada por ciudadanos europeos.

12 Lo cual remite a la naturaleza desigual de las relaciones de poder y saber dentro de la propia Europa, dado que a la par que existe un discurso eurocéntrico "hacia el exterior", también es llevado a cabo un discurso occidentalizante "hacia el interior" que inferioriza las "multiples Europas" no hegemónicas (países del Sur y el Este europeo, miembros de la UE o en proceso de ingreso), las cuales son consideradas un "yo incompleto" de la más moderna y desarrollada Europa “heroica” Norte-Occidental hegemónica (Boatcă, 2010: 201 y 204). 
"ego-política del conocimiento" (Grosfoguel, 2007: 37) implícita en esta epistemología. En efecto, el acercamiento cientifista de la UE reproduce la idea de un sujeto cartesiano capaz de aprehender la realidad "tal como es", un sujeto que produce enunciados con validez universal desde la "presunción de un punto cero" (Castro-Gómez, 2007). La "geopolítica" y "corpopolítica" que implica todo conocimiento (Mignolo, 2010: 10) son suprimidas, "el sujeto cognoscente [...] está apartado de lo que conoce y no es tocado por la configuración geopolítica de un mundo en donde las personas y las regiones mundiales son clasificadas racialmente" (Mignolo, 2010: 9). Así pues, el sujeto del conocimiento se convierte en un "observador desapegado, un buscador de verdades y objetividades neutral, que al mismo tiempo controla las reglas disciplinarias y se sitúa (él o ella) en una posición privilegiada para evaluar y definir" (Mignolo, 2010: 14).

Un ejemplo muy llamativo de esta egopolítica del conocimiento es el planteamiento, muy difundido entre los actores comunitarios, de que el racismo es sustancialmente una cuestión de "percepciones falsas" y "falta de información" 13 sobre la características de la presencia inmigrante por parte de la población europea (véase Comisión Europea, 2010: 51). En primer lugar, este postulado insiste en un argumento profundamente clasista, que desautoriza todo tipo de saber "emocional" o "irracional" y lo relega al terreno del "saber popular" plebeyo -contrapuesto al "saber experto" de los think tank bruselenses-. He aquí una analogía con la descalificación etnocéntrica de todo conocimiento exótico producido por el Otro colonial, la cual resalta la estrecha imbricación existente entre "clase" y "raza" (véase Balibar, 1988) y muestra la subsistencia tanto de un "racismo epistemológico" (Grosfoguel y Mielants, 2006. Grosfoguel, 2007) como de un "clasismo epistemológico". En segundo lugar, resulta paradójico achacar la difusión del racismo a una falta de conocimiento "objetivo" de la realidad en los términos propuestos, cuando los orígenes históricos de las doctrinas del "racismo científico" han de encontrarse justamente en las instituciones académicas y del "saber experto" occidentales ${ }^{14}$. Finalmente, este ejemplo es útil para destacar el profundo "logocentrismo" (Walsh, 2012: 56) ínsito en esta epistemología, con sus tajantes dualismos razón/emoción y mente/cuerpo (véase Lander, 2008: 250), donde sólo a los primeros términos de las oposiciones es adscrita una capacidad cognoscitiva, siendo los segundos términos el lugar de una política "populista", anti-científica y necesariamente abocada al fracaso o al desastre ${ }^{15}$.

En resumen, desde el Marco Europeo de la Integración se produce un apabullante desconocimiento (o no reconocimiento) de epistemologías otras. Las categorías de conocimiento elaboradas en este espacio, presentadas como "neutrales" aunque en realidad supeditadas a los objetivos comunitarios -y a veces incluso derivadas directamente de las categorías jurídicas de las políticas públicas ${ }^{16}{ }_{-}$, funcionan excluyendo, invisibilizando o marginalizando prácticas y saberes contrahegemónicos "otros". Se trata de un conocimiento "mal llamado 'experto', negador y detractor de las prácticas, agentes y saberes que no caben dentro de la racionalidad hegemónica y dominante" (Walsh, 2012: 57).

13 Mi interés por esta cuestión origina de la crítica de Žižek a la conceptualización del racismo en tanto problema de desconocimiento (2010: 39-40), aunque se diferencia de este autor al alejarse del marco psicoanalítico por él propuesto.

14 Debo esta última reflexión a un intercambio de ideas con Ariana S. Cota.

15 Cabe añadir que la capacidad productiva y políticamente positiva de las emociones ha sido reconocida incluso desde planteamientos internos al paradigma de la Modernidad, véase por ejemplo Mouffe (2007).

16 Un ejemplo de esto es el "Immigrant Citizens Survey", una investigación realizada por el think tank "Migration Policy Group" orientada a conocer las necesidades de las personas inmigrantes en la UE y sin embargo basada exclusivamente en entrevistas a "nacionales de terceros países residentes legalmente". 


\subsection{La colonialidad del saber como "mediación"}

El Marco Europeo para la Integración, a pesar de ser presentado como un espacio de implicación y ciudadanía activa, está caracterizado por unas formas de conocimiento ampliamente imbuidas de colonialidad del saber. Si en las políticas comunitarias de control migratorio se da una oscilación entre lo tecnológico/militar y lo tecnocrático, aquí hay una tensión entre el llamamiento a la participación activa y una creciente tecnificación de los saberes bajo cuyos supuestos dicha participación tiene lugar. Por un lado tecnologías materiales y concretas "de control", por el otro tecnologías participativas "de gobierno" 17 fundadas en saberes, procedimientos y racionalidades específicas. Es en virtud de estas "mediaciones" que la colonialidad del saber se muestra, en este último ámbito, de una manera menos directa y evidente. Para utilizar la terminología de Santos, podría decirse que las políticas de control migratorio comunitarias representan el dominio de la dicotomía "apropiación" vs. "violencia" típica de la experiencia colonial occidental, mientras que el discurso de la integración remite al imaginario interno a las sociedades metropolitanas, caracterizado por la dicotomía "regulación social" vs. "emancipación social". No obstante, también en este último espacio se vislumbra la inquietante presencia de una "violencia epistémica" (Castro-Gómez, 2000) que, como observa el sociólogo portugués, suele aparecer "siempre que relaciones de poder muy desiguales están involucradas" (Santos, 2010: 28). Tal como afirma (aunque en relación con otro contexto) Rivera: "Hoy en día, la retórica de la igualdad y la ciudadanía se convierte en una caricatura que encubre privilegios políticos y culturales tácitos, nociones de sentido común que hacen tolerable la incongruencia y permiten reproducir las estructuras coloniales de opresión" (Rivera, 2010).

\section{Conclusiones provisionales: diferentes mecanismos, igual fundamento. La separa- ción inmigración/integración como tecnología de poder con una dimensión de colonia- lidad}

En este apartado juntaré las diferentes "piezas" de este puzle y trataré de articular una reflexión sobre el conjunto de las cuestiones tratadas. Para empezar, en los anteriores apartados he ilustrado las diferentes lógicas de colonialidad que influyen en las políticas de control migratorio y de integración. He afirmado que la violencia que acontece en las multiples fronteras europeas -ejercida sobre un Otro marcado por la diferencia colonial, inferiorizado y racializado- parece ser la otra cara de la moneda con respecto del espacio de "modernización" que se abre para el/la migrante en el campo de la integración. Es más, sin ese imaginario de "barbarie", la propia idea de "civilización", que es su contraparte, no podría existir siquiera (Castro-Gómez, 2000: 91). De ahí la necesidad de la existencia de un "aquí" y "allî", términos antaño coincidentes con lugares geográficos -la metrópolis y sus colonias-, pero cada vez más entendibles como "espacios representacionales" en la época de la globalización y de las migraciones transnacionales ${ }^{18}$. "Allíl, las políticas de control se encargan de los "necesarios" sacrificios. Da igual que sean indirectos, basados en la no-acción, por la simple determinación de ciertas prioridades políticas o debido a los "fallos" de los aparatos tecnológicos de control. "Aquî", la misión "civilizadora" se

17 Desde la perspectiva de los estudios sobre gubernamentalidad son tecnologías "de poder" o "de gobierno" todos aquellos ensamblajes de cosas, personas, discursos y prácticas caracterizados por una capacidad de agencia, por una disposición a la "traducción" y a la "alineación" de los objetivos establecidos por los actores hegemónicos con la conducta de las personas y los grupos subalternos. En última instancia, representan una forma de perpetuación de las relaciones de poder (véase Rose, 1999: 52).

18 Retomando la distinción de Coronil entre "Occidentalismo" y "Orientalismo", puede decirse en la misma línea que los términos "aquí" y "allí" no son dos simples "opuestos", dado que se fundamentan en una jerarquización "cultural" y "racial" vinculada a la existencia de relaciones de poder/saber desiguales y asimétricas a nivel global. Son más bien uno el presupuesto del otro (véase Coronil, 1996: 56). 
encarga minuciosamente de desplegar un conjunto de prácticas y saberes dirigidos a su integración. "Allî" predomina y se manifiesta la colonialidad el poder, "aquí" se infiltra más discretamente la colonialidad del saber. "Allî" los migrantes no comunitarios son sujetos pasivos, o cuando menos a pasivizar, cuyo "activismo" y "participación" fuera de los estrechos márgenes legales es duramente reprimido y condenado -como recuerda Mignolo, la diferencia colonial tiene un lugar pasivo en los discursos posmodernos (y modernos) (2000: 36)-. "Aquî", en cambio, pasados los primeros "filtros selectivos" fronterizos (Mezzadra y Nielson, 2014) y entrados en los espacios de "regulación” y "emancipación”, ellos/ellas se convierten en individuos potencialmente "autónomos" y "hacedores de sí mismos", cuyo protagonismo como miembros de la "sociedad civil" es ensalzado -aunque, como hemos visto, dentro de un marco limitado-. De ahí la necesidad de establecer otra frontera -social y (geo)política antes que geográfica- que permita comprobar el alcance de esa meta: llámese integración. Hablando en términos fanonianos ${ }^{19}$, las políticas de integración parecen ser un canal de acceso a la "zona del Ser", ya que hacen posible para la persona migrante no comunitaria una especie de transición hacia "el lado superior de la línea de lo humano" (Grosfoguel, 2011: 99); mientras que las de control migratorio se asemejan más bien a un dispositivo para la administración de la salida o el retorno hacia las "zonas del no-ser" -aquéllas caracterizadas por el "no reconocimiento de la humanidad del otro" (Grosfoguel, 2011: 100)- para todos aquellos migrantes que "fracasen" en el proceso de integración, que no logren "constituirse" como individuos "emancipados" y vuelvan a ser objeto de una práctica de racialización/inferiorización arraigada en su procedencia "cultural" 20 .

Ahora bien, ¿cómo es posible que dos lógicas (aparentemente) tan diferentes operen simultáneamente dentro de la misma realidad social y política? ¿Cómo puede la UE compaginar ciertos discursos "políticamente correctos" sobre la antidiscriminación, el antirracismo o el elogio a la diversidad -por mucha colonialidad del saber que pueda haber en ellos- con la materialidad de la violencia que se perpetra en las fronteras? Para avanzar una respuesta, rescataré una anécdota de mi trabajo de campo. Durante una entrevista con el representante de una organización humanitaria, y después de haberle aclarado que mi interés eran las políticas del Marco Europeo para la Integración, pregunté a mi interlocutor por la ya mencionada "Directiva de Retorno". Ante lo cual él me dijo: "¿Qué tiene que ver la Directiva de retorno con la integración?" (entrevista del 11/6/2012. Traducción propia). Esto evidencia la existencia de una lógica discursiva que diferencia netamente entre el ámbito de la inmigración y el de la integración, a pesar de las numerosas conexiones más o menos "subterráneas" existentes. Para la persona entrevistada, la objeción era correcta desde un punto de vista formal. Aun así, sería difícil sostener que una medida como la citada, al afectar -entre otras cosas- la libertad de circulación por el espacio público de una gran cantidad de personas, no influye en sus posibilidades sustanciales de integración. En otras palabras, operar la distinción tan puntual entre "políticas de integración" y "políticas de control migratorio" equivale a forzar una separación discursiva entre dos realidades cuyas fronteras son muy borrosas e inciertas. Conlleva naturalizar el hecho, históricamente innegable pero producto de decisiones políticas, de que las políticas de control migratorio son hoy día el cimiento sobre el que se construyen las demás intervenciones dirigidas a la migración no comunitaria. Es por eso que, ya en mi tesis doctoral, interpretaba la diferenciación entre

19 La negación del Otro llevada a cabo por el pensamiento abismal es radical y no dialéctica. En la re-lectura fanoniana de la dialéctica hegeliana entre amo y esclavo, en el contexto colonial, no hay reconocimiento recíproco, dado que el esclavo es considerado "subhumano" por el amo-colonizador "humano" (véase Fanon, 1996: 188-193).

20 "Dado que el mercado se presenta como una estructura de posibilidades en vez de como un régimen de dominación, éste crea la ilusión de que la acción humana es libre y no limitada. Resultados como la marginalización, el desempleo y la pobreza aparecen como fallas individuales o colectivas, en vez de como efectos inevitables de una violencia estructural" (Coronil, 2000: 63). 
inmigración e integración como una tecnología de poder/saber que funciona restringiendo los márgenes para el pensamiento y la acción ante una realidad tan difícilmente escindible en fases separadas como es la movilidad humana. Avanzando en la tarea de "tropicalizar" los estudios sobre gubernamentalidad, puedo ahora decir que, además de todo esto, se trata de una tecnología de poder/saber atravesada por una fuerte dimensión de colonialidad. En efecto, la manera en la que nos empuja a pensar produce una desarticulación entre esos dos momentos de la experiencia migratoria, en realidad complementarios y mutuamente constitutivos $^{21}$. Además, esta separación produce una "inocentización" de la UE, dado que la propia existencia de un ámbito específico de políticas llamado "integración” trasmite la idea de que "se está haciendo algo", "estamos interviniendo", "nosotros somos abiertos, inclusivos y civilizados, mientras que 'ellos' no" (entrevista del 12/6/2012. Traducción propia), cumpliendo una función simbólica, identitaria y encubridora tanto de la colonialidad del poder ejercido como del saber generado ${ }^{22}$. Adoptando la terminología propuesta por Lugones, la distinción "inmigración” vs. "integración” es conceptualizable como una separación categorial, esto es, una operación que presenta como separadas (y separables) categorías que en la experiencia social se encuentran imbricadas, categorías que lejos de ser intercambiables como meros sumandos producen configuraciones específicas según cómo se articulen en cada caso. Dicha separación (en el texto de Lugones relativa a las categorías de raza, género, clase y sexualidad) no permite entender el funcionamiento de las categorías; es más, lo oculta (Lugones, 2010: 58).

Para concluir: las políticas públicas de la Unión Europea están atravesadas por una invisible línea abismal, la cual produce "integración" y "control migratorio" como dos cosas diferentes, no relacionadas, ocultando su profunda interconexión. Tanto el funcionamiento de esta "separación categorial" -interpretable como una tecnología de poder/saber atravesada por una dimensión de colonialidad- como las lógicas dominantes en cada uno de los dos ámbitos alientan una difuminación del lugar de enunciación de las susodichas políticas ${ }^{23}$. En el contexto de las políticas de control migratorio, este lugar de enunciación resulta difícil de suprimir completamente debido a la inmediatez con la que la colonialidad del poder se presenta. Las crecientes tecnocratización, externalización y desresponsabilización operantes en este espacio político constituyen también una forma, no totalmente efectiva, para tratar de conseguirlo. Por otra parte, en el marco de la integración la colonialidad del saber se presenta mediada, al encontrarse imbricada en un conjunto de prácticas participativas y formas de conocimiento/intervención. Tales prácticas contribuyen a difuminar, hasta ocultar o cuando menos encubrir más eficazmente, la "ego-política del conocimiento" y el lugar etnocéntrico desde el que son enunciadas.

\section{Bibliografía}

AGAMBEN, Giorgio

2004 Estado de excepción. Homo sacer II, 1. Valencia: Pre-textos.

AMNISTÍA INTERNACIONAL

2011 Parad el racismo, no a las personas. Perfiles raciales y control de la inmigración en españa. Madrid: Amnistía Internacional, en http://gestionpolicialdiversidad.org/PDFdo-

21 Aunque no haya espacio para fundamentarlo, lo mismo podría decirse de la separación entre migrantes "regulares" e "irregulares".

22 No de casualidad, en mi propia experiencia he podido escuchar varias veces el refrán "queremos más integración", pronunciado por actores alternativos y entendido como algo contrapuesto, y fundamentado en una crítica, a las políticas migratorias existentes.

23 En términos más generales puede afirmarse que las tecnologías de poder neoliberales y los discursos típicos de la globalización, diferentemente de los que los precedieron, no se componen de "metarelatos que muestran al sistema, proyectándolo ideológicamente en un macrosujeto epistemológico, histórico y moral, sino de microrelatos que lo dejan por fuera de la representación, es decir, que lo invisibilizan" (Castro-Gómez, 2000: 95). 
cumentos/Parad_el_racismo_no_a_las_personas.pdf (Consulta: 06-06-2015).

ANDERSSON, Ruben

2014 Illegality, Inc. Clandestine Migration and the Business of Bordering Europe. Oakland: University of California Press.

ARMSTRONG, Kenneth

2001 "Civil Society and the White Paper - Bridging or Jumping the Gaps?", en Symposium "Mountain or Molehill? A Critical Appraisal of the Commission White Paper on Governance”, Jean Monnet Working Paper No.6/01.

BALIBAR, Étienne

1988 "El racismo de clase", en Wallerstein, I. y Balibar, E. (eds.), Raza, Nación y Clase: 313334. Madrid: Iepala.

2003 “Apertura. En las fronteras de Europa”, en Balibar, E., Nosotros, ¿ciudadanos de Europa? Las fronteras, el estado, el pueblo: 19-30. Madrid: Tecnos.

2009 "Ideas of Europe: Civilization and Constitution", en European Journal of Philosophy and Public Debate, 1 (1), 3-17, en http://www.fupress.net/index.php/iris/article/view/2854 (Consulta: 06-06-2015).

BOATC $\breve{A}$, Manuela

2010 "Múltiples Europas y la mística de la unidad", en Cairo, H. y Grosfoguel, R. (eds.), Descolonizar la modernidad, descolonizar Europa. Un diáogo Europa-América Latina: 193208. Madrid: IEPALA.

BOATCĂ, Manuela; COSTA, Sérgio; GUTIÉRREZ RODRÍGUEZ, Encarnación.

2010 "Introduction. Decolonizing European Sociology: Different Paths towards a Pending Project”, en Gutiérrez Rodríguez, E., Boatcă, M. y Costa, S. (eds.), Decolonizing European Sociology. Transdisciplinary Approaches: 1-10. Surrey: Ashgate.

\section{BRIGADAS VECINALES DE OBSERVACIÓN DE DERECHOS HUMANOS}

2012 Cuando la vulneración de derechos se normaliza. Controles de identidad racistas en Madrid. Madrid: Brigadas Vecinales de Observación de Derechos Humanos, en http://brigadasvecinales.org/wp-content/uploads/2012/12/Informe-Brigadas-Vecinales-2011-2012. pdf (Consulta: 06-06-2015).

CARRERA, Sergio; PARKIN, Joanna

2010 "The Place of Religion in European Union Law and Policy. Competing Approaches and Actors inside the European Commission", en RELIGARE Working Document, 1, en http:// www.ceps.eu/system/files/book/2010/09/RELIGARE\%20-\%20Religion\%20and\%20 the\%20EU_Final.pdf (Consulta: 06-06-2015).

CASAS, Maribel; COBARRUBIAS, Sebastian; PICKLES, John

2011 "Stretching Borders Beyond Sovereign Territories? Mapping EU and Spain's Border Externalization Policies", en Geopolítica(s), 2(1), 71-90.

CASTRO-GÓMEZ, Santiago

2000 "Ciencias sociales, violencia epistémica y el problema de la 'invención del otro"”, en Lander, E. (ed.), La colonialidad del saber: eurocentrismo y ciencias sociales. Perspectivas latinoamericanas: 88-98. Buenos Aires: Clacso.

2007 "The Missing Chapter of Empire. Postmodern reorganization of coloniality and post-Fordist capitalism", en Cultural Studies, 21(2-3), 428-448.

CÉSAIRE, Aimé

2006 "Carta a Maurice Thorez", en Césaire, A., Discurso sobre el colonialismo: 77-84. Madrid: Akal.

CHAKRABARTY, Dipesh

2008 Al margen de Europa. Pensamiento poscolonial y diferencia histórica. Barcelona: Tusquets.

$\operatorname{COM}(2015) 240$ final.

2015 Comunicación de la Comisión Europea “Una agenda europea de migración”, en http:// ec.europa.eu/dgs/home-affairs/what-we-do/policies/european-agenda-migration/background-information/docs/communication_on_the_european_agenda_on_migration_ es.pdf (Consulta: 06-06-2015).

COMISIÓN EUROPEA

2010 Manual sobre la integración para responsables de la formulación de políticas y profesio- 
nales. Tercera edición. Bruselas: Unión Europea, en http://www.fvgsolidale.regione.fvg. it/infocms/repositPubbl/table3/50/allegati/Integration_Handbook_III_ES_15.04.10.pdf (Consulta: 06-06-2015).

CONSEJO DE LA UNIÓN EUROPEA

2004 Sesión número 2618 del Consejo de Justicia y Asuntos de Interior, 19/11/2004, en http:// www.consilium.europa.eu/uedocs/cms_data/docs/pressdata/es/jha/82875.pdf (Consulta: 06-06-2015).

CORONIL, Fernando

1996 "Beyond Occidentalism: Toward Nonimperial Geohistorical Categories", en Cultural Anthropology, 11(1): 51-87, en http://www.jstor.org/stable/656209 (Consulta: 06-062015).

2000 "Naturaleza del poscolonialismo: del eurocentrismo al globocentrismo", en Lander, E. (ed.), La colonialidad del saber: eurocentrismo y ciencias sociales. Perspectivas latinoamericanas: 53-67. Buenos Aires: Clacso.

CÚE, Carlos; JIMÉNEZ GÁLVEZ, José María

2014 "La Guardia Civil ocultó en sus informes la carga con pelotas de goma en el agua", en El País.com, http://politica.elpais.com/politica/2014/02/19/actualidad/1392845602_918392.html (Consulta: 06-06-2015).

DAL LAGO, Alessandro

2005 "Frentes y fronteras: notas sobre la militarización de la contigüidad", en Alteridades, 15(30): 43-49.

DEAN, Mitchell

2010 Governmentality. Power and Rule in a Modern Society. London: Sage.

DE GENOVA, Nicholas

2015 "The border spectacle of migrant "victimisation"”, en OpenDemocracy, https://www. opendemocracy.net/beyondslavery/nicholas-de-genova/border-spectacle-of-migrant$\%$ E2\%80\%98victimisation\%E2\%80\%99 (Consulta: 06-06-2015).

DUSSEL, Enrique

2000 "Europa, modernidad y eurocentrismo", en Lander, E. (ed.), La colonialidad del saber: eurocentrismo y ciencias sociales. Perspectivas latinoamericanas: 24-33. Buenos Aires: Clacso.

FANON, Frantz

1996 Pelle nera maschere bianche. Il nero e l'altro. Milano: Marco Tropea Editore.

FOUCAULT, Michel

1991 "Governmentality", en Burchell, G.; Gordon, C.; Miller, P. (eds.), The Foucault Effect. Studies in governmentality. With two lectures by and an interview with Michel Foucault: 87-104. Chicago: University of Chicago Press.

2009 Las palabras y las cosas: una arqueología de las ciencias humanas. Madrid: Siglo XXI. GARCÍA, Ter

2015 “Aprobadas definitivamente la 'Ley Mordaza' y la reforma del Código Penal”, en Diagonal Periódico.net, https://www.diagonalperiodico.net/libertades/26208-aprobacion-definitiva-la-ley-seguridad-ciudadana-y-la-reforma-del-codigo-penal.html (Consulta: 06-062015).

GARELLI, Glenda; TAZZIOLI, Martina

2013 "Challenging the disciplin of migration: militant research in migration studies, an introduction", en Postcolonial Studies, 16(3): 245-249, en http://www.tandfonline.com/doi/ab GIL, Sandra s/10.1080/13688790.2013.850041\#.VXLh_M_tmko (Consulta: 06-06-2015).

2003 "Las migraciones en las políticas de la fortaleza. Sobre las multiples fronteras de la Europa Comunitaria", en Gil, S.; Dahiri, M. (eds.), Movimientos migratorios en el Mediterráneo Occidental. ¿Un fenómeno o un problema? Córdoba: Ayuntamiento de Córdoba.

2006 Las argucias de la integración. Tesis doctoral. Madrid: Universidad Complutense de Madrid.

2010 "The Coloniality of Power and Ethnic Affinity in Migration Policy: The Spanish Case", en Gutiérrez Rodríguez, E.; Boatcă, M.; Costa, S. (eds.), Decolonizing European Sociology. Transdisciplinary Approaches: 179-193. Surrey: Ashgate. 
GROSFOGUEL, Ramón

2007 "Los dilemas de los estudios étnicos estadounidenses: multiculturalismo identitario, colonización disciplinaria y epistemologías decoloniales", en Universitas humanística, 63: 35-47.

2010 "Descolonizar los uni-versalismos occidentales: el pluri-versalismo transmoderno decolonial de Aimé Césaire a los zapatistas", en Cairo, H.; Grosfoguel, R. (eds.), Descolonizar la modernidad, descolonizar Europa. Un diáogo Europa-América Latina: 85-99. Madrid: IEPALA.

2011 "La descolonización del conocimiento: diálogo crítico entre la visión descolonial de Frantz Fanon y la sociología descolonial de Boaventura de Sousa Santos", en Actas del IV Training Seminar del Foro de Jóvenes Investigadores en Dinámicas Interculturales, CIDOB, Barcelona, 26-28/1/2011.

GROSFOGUEL, Ramón; MIELANTS, Eric

2006 "The Long-Durée Entanglement Between Islamophobia and Racism in the Modern/Colonial Capitalist/Patriarchal World-System", en Human Architecture: Journal of the Sociology of Self-Knowledge, 1: 1-12.

KRAMSCH, Olivier

2010 “'Dans le balon rouge?' Entre el proyecto modernidad/colonialidad latinoamericano y la Europa fronteriza realmente existente", en Cairo, H.; Grosfoguel, R. (eds.), Descolonizar la modernidad, descolonizar Europa. Un diáogo Europa-América Latina: 257-274. Madrid: IEPALA.

LANDER, Edgardo

2000a La colonialidad del saber: eurocentrismo y ciencias sociales. Perspectivas latinoamericanas. Buenos Aires: Clacso.

2000 b "Ciencias sociales: saberes coloniales y eurocéntricos", en Lander, E. (ed.), La colonialidad del saber: eurocentrismo y ciencias sociales. Perspectivas latinoamericanas: 4-23. Buenos Aires: Clacso.

2008 La ciencia neoliberal. Tabula Rasa, 9: 247-283.

LUGONES, María

2010 "Colonialidad y género", en Cairo, H.; Grosfoguel, R. (eds.), Descolonizar la modernidad, descolonizar Europa. Un diáogo Europa-América Latina: 57-83. Madrid: IEPALA.

MARCECA, Romina; VIVIANO, Francesco; ZINITI, Alessandra

2015 "Strage al largo della Libia: morti in mare tra 700 e 900 migranti, solo 28 superstiti. E' la tragedia più grande di sempre", en Repubblica.it, palermo.repubblica.it/cronaca/2015/04/19/news/almeni_700_migranti_morti_in_un_naufragio_a_nord_della_libia_ solo_28_superstiti-112315076/ (Consulta: 06-06-2015).

MEZZADRA, Sandro; NIELSON, Brett

2014 "Fronteras de inclusión diferencial. Subjetividad y luchas en el umbral de los excesos de justicia", en Papeles del CEIC, 2014(2): 1-30.

MIGNOLO, Walter

2000 "La colonialidad a lo largo y lo ancho: el hemisferio occidental en el horizonte colonial de la modernidad", en Lander, E. (ed.), La colonialidad del saber: eurocentrismo y ciencias sociales. Perspectivas latinoamericanas: 34-52. Buenos Aires: Clacso.

2003 Historias locales/diseños globales. Colonialidad, conocimientos subalternos y pensamiento fronterizo. Madrid: Akal.

2010 "Desobediencia Epistémica (II), Pensamiento Independiente y Libertad De-Colonial”, en MIGREUROP Otros Logos Revista de Estudios Críticos, 1(1): 8-42.

2014 "Cartografía de los campos de extranjeros", en http://es.closethecamps.org/ (Consulta: 0606-2015).

MOUFFE, Chantal

2007 En torno a lo político. Buenos Aires: Fondo de Cultura Económica.

ORDAZ, Pablo

2015 "700 inmigrantes desaparecidos tras hundirse su barcoenaguas libias", en El País.com, http:// internacional.elpais.com/internacional/2015/04/19/actualidad/1429431225_038632.html (Consulta: 06-06-2015). 
QUIJANO, Aníbal

2000 "Colonialidad del poder, eurocentrismo y América Látina", en Lander, E. (ed.), La colonialidad del saber: eurocentrismo y ciencias sociales. Perspectivas latinoamericanas: 122-152. Buenos Aires: Clacso.

REDAZIONE HUFFINGTON POST

2015 "Daniela Santanchè: 'Bisogna affondare i barconi. Meglio un atto di guerra che perdere la guerra'”, en Huffington Post.it, http://www.huffingtonpost.it/2015/04/19/daniela-santan-

REPUBBLICA.IT che-barconi_n_7094910.html (Consulta: 06-06-2015).

2015a "Strage migranti, organizzazioni umanitarie: 'Serve Mare Nostrum europea”, en http:// www.repubblica.it/solidarieta/immigrazione/2015/04/19/news/triton_mare_nostrum_organizzazioni_umanitarie-112360667/ (Consulta: 06-06-2015).

2015b "Strage migranti, Papa: 'Comunità internazionale agisca decisa'. Salvini: 'Subito blocco navale"," en www.repubblica.it/politica/2015/04/19/news/naufragio_nel_canale_di_sicilia_salvini_servono_altri_700_morti_per_bloccare_le_partenze_-112320076/ (Consulta: 06-06-2015).

RIVERA CUSICANQUI, Silvia

2010 Ch'ixinakax utxiwa. Una reflexión sobre prácticas y discursos descolonizadores, en https://chixinakax.wordpress.com/2010/07/22/ch\%E2\%80\%99ixinakax-utxiwa-una-reROSE, Nikolas flexion-sobre-practicas-y-discursos-descolonizadores/ (Consulta: 06-06-2015).

1999 Powers of freedom. Reframing political thought. Cambridge: Cambridge University Press. SAID, Edward

1990 Orientalismo. Madrid: Libertarias.

SANTAMARÍA, Enrique

2002 La incógnita del extraño. Una aproximación a la significación sociológica de la inmigración no comunitaria. Barcelona: Anthropos.

SANTOS, Boaventura de Sousa

2010 Para descolonizar Occidente. Más allá del pensamiento abismal. Buenos Aires: Clacso.

SHORE, Cris; WRIGHT, Susan

1997 Anthropology of Policy. Critical perspectives on Governance and power. London: Routledge.

URBÁN, Miguel

2015 "El Mediterráneo queda muy lejos de Bruselas", en Público.es, http://blogs.publico.es/ tomar -partido/2015/04/23/el-mediterraneo-queda-muy-lejos-de-bruselas/ (Consulta: 0606-2015).

VAN ÖERS, Ricky; ERSBØLL, Eva; KOSTAKOPOULOU, Dora

2010 A redefinition of belonging? Language and Integration Tests in Europe. Leiden: Martinus Nijhoff.

WALLERSTEIN, Immanuel

1996 "El eurocentrismo y sus avatares: los dilemas de las ciencias sociales", en Coloquio "El futuro de la sociología en el este de Asia”, Asociación Coreana de Sociología y Asociación Internacional de Sociología, Seúl, 22-23/11/1996, en http://newleftreview.es/article/

WALSH, Catherine download_pdf?language=es\&id=1934\%E2\%80\%8E (Consulta: 06-06-2015).

2012 ¿Son posibles unas ciencias sociales/culturales otras? reflexiones en torno a las epistemologías decoloniales", en Arribas, A.; García-González, N.; Álvarez, A.; Ortega, A. (eds.), Tentativas, contagios, desbordes. Territorios del pensamiento: 55-71. Granada: Universidad de Granada.

ŽIŽEK, Slavoj

2010 En defensa de la intolerancia. Madrid: Público. 